\title{
Early cognitive function, recovery and well-being after sevoflurane and xenon anaesthesia in the elderly: a double-blinded randomized controlled trial
}

Jan Cremer, Christian Stoppe, Astrid V Fahlenkamp, Gereon Schälte, Steffen Rex, Rolf Rossaint and Mark Coburn*

\begin{abstract}
Background: The postoperative cognitive function is impaired in elderly patients after general anaesthesia. The fast recovery after xenon anaesthesia was hypothesized to be advantageous in this scenario. We compared early postoperative cognitive function after xenon and sevoflurane anaesthesia in this study.

Methods: The study was approved by the local ethics committee and written informed consent was obtained from each patient. Patients aged 65-75 years (ASA I-III) scheduled for elective surgery (duration 60-180 min) were enrolled. Investigators performing cognitive testing and patients were blinded towards allocation to either xenon or sevoflurane anaesthesia. Baseline assessment of cognitive function was carried out $12-24 \mathrm{~h}$ before the operation. The results were compared to follow-up tests 6-12 and 66-72 h after surgery. Primary outcome parameter was the subtest "Alertness" of the computerized Test of Attentional Performance (TAP). Secondary outcome parameters included further subtests of the TAP, several Paper-Pencil-Tests, emergence times from anaesthesia, modified Aldrete scores and patients' well-being.
\end{abstract}

Results: 40 patients were randomized and equally allocated to both groups. No significant differences were found in the TAP or the Paper-Pencil-Tests at 6-12 and 66-72 $\mathrm{h}$ after the operation. All emergence times were faster after xenon anaesthesia. The modified Aldrete scores were significantly higher during the first hour in the xenon group. No difference in well-being could be detected between both groups.

Conclusions: The results show no difference in the incidence of postoperative cognitive dysfunction (POCD) after xenon or sevoflurane anaesthesia. Emergence from general anaesthesia was faster in the xenon group.

\section{Introduction}

Age is a known risk factor for postoperative cognitive dysfunction (POCD) after cardiac and non-cardiac surgery [1-3]. Up to $41 \%$ of patients aged 60 years and older are affected by POCD and exposed to an increased risk of death within the first 12 months after major noncardiac surgery [1].

Although a growing number of researchers are concentrating on POCD [4], no significant progress can be seen in the prevention of POCD.

\footnotetext{
* Correspondence: mcoburn@ukaachen.de

Department of Anaesthesiology, University Hospital Aachen of the RWTH Aachen, Pauwelsstraße 30, D-52074 Aachen, Germany

Aachen, Pauwelsstraße 30, D-52074 Aachen, Germany
}

The noble gas xenon offers good haemodynamic stability [5-10] and favours rapid recovery from anaesthesia $[11,12]$, both of which have been hypothesized to be beneficiary in the reduction of POCD [13-15]. Xenon is a safe anaesthetic agent $[12,16,17]$ which has been approved for clinical use in Germany (ASA I-III patients) since 2005 and in Europe (ASA I-II patients) since 2007 [18]. Its remarkable potential of neuronal protection has been demonstrated in several in vivo and in vitro models of ischemic and traumatic neuronal injury [19-24].

This study was conducted to investigate early postoperative cognitive function in elderly patients after general anaesthesia, hypothesizing a positive influence by use of xenon compared to sevoflurane.

(c) 2011 Cremer et al; licensee BioMed Central Ltd. This is an Open Access article distributed under the terms of the Creative Commons
Attribution License (http://creativecommons.org/licenses/by/2.0), which permits unrestricted use, distribution, and reproduction in any medium, provided the original work is properly cited. 
Confirmation of this hypothesis would be an important step towards establishing strategies for the prevention and reduction of POCD.

\section{Methods}

The study was designed as a prospective, inpatient, double-blinded, randomized, controlled trial. It was conducted at the University Hospital Aachen, Germany after obtaining approval from the local ethics committee.

Random assignment of the patients to either the sevoflurane or xenon anaesthesia group was achieved by using a computer-generated allocation sequence. Study investigators and patients were blinded in terms of group assignment. It was not feasible to blind the anaesthetist due to the different administration methods of the anaesthetics.

Primary outcome parameter of this study was the cognitive function, which was assessed with the subtest "Alertness" of the computerized Test for Attentional Performance (TAP, Version 1.7; Psytest, 2002).

As described previously, several other subtests of the TAP and additional Paper-Pencil-Tests were selected to monitor a wide spectrum of cognitive functions $[13,15,25,26]$.

The set of Paper-Pencil-Tests included the Digit-Symbol-Substitution-Test (DSST), Recall of Digit Span (DS) and the Trail Making Tests A and B [27-29].

Anxiety and Depression were measured with the Wellbeing Test Bf-S and the short form of the Spielberger State-Trait Anxiety Inventory (STAI) [30,31].

Secondary outcome parameters were the emergence times from anaesthesia and the modified Aldrete scores recorded in the post-anaesthetic care unit (PACU) [32]. Levels of vigilance, well-being and energy were also assessed in the PACU.

Patients were assessed for eligibility and gave informed written consent to participating in the trial. A total of 40 patients, aged 65-75 years, and ASA status I-III were enrolled in this study. Patients were excluded from the trial in case of diabetes mellitus, congestive heart failure, adrenal insufficiency, reduced renal and/or hepatic function, chronic alcohol or drug abuse, disabling neuropsychiatric disorders, increased intracranial pressure, a history of stroke, cardiopulmonary resuscitation or brain trauma within the past 12 months, anaphylactic reactions to anaesthetics, legal incapacity, a lack of cooperation or the need for emergency operations.

The elective surgical operations under general anaesthesia were planned for $60-180 \mathrm{~min}$ and scheduled in urology, gynaecology, neurosurgery, trauma, ENT, orthopaedics and abdominal surgery. Neurosurgery was limited to interventions on the spine.

Management of anaesthesia followed standardised instructions, identical for both groups. Following a 3 min period of preoxygenation $\left(100 \% \mathrm{O}_{2}\right)$, anaesthesia was induced through a single slow i.v. injection of propofol $\left(2 \mathrm{mg} \mathrm{kg}^{-1}\right)$ and simultaneous infusion of remifentanil $\left(0.5 \mu \mathrm{g} \mathrm{kg}^{-1}\right.$ over $\left.60 \mathrm{~s}\right)$. Facilitation of tracheal intubation was achieved with rocuronium $\left(0.6 \mathrm{mg} \mathrm{kg}^{-1}\right)$.

Standard monitoring of the patients included pulse oximetry, three-lead ECG, non-invasive blood pressure, temperature (AS/3 monitor, GE Datex-Ohmeda, Helsinki, Finland), bispectral index monitoring (BIS Model A $2000^{\circledR}$, Software Version 2.21, Aspect Medical Systems, Boston, MA, USA) and end-tidal concentrations of oxygen, carbon dioxide and anaesthetic gases. All parameters were recorded at fixed intervals of $5 \mathrm{~min}$.

Maintenance of anaesthesia was achieved by either xenon or sevoflurane. Administration of sevoflurane was started with age-adapted equipotent MAC values of 1 with 1.1-1.4 vol\% in 30\% oxygen (Cato ${ }^{\circledR}$, Draeger, Lübeck, Germany) [33].

Xenon was started at $60 \%$ xenon in $30 \%$ oxygen and administered with a close circuit anaesthesia machine (Physioflex ${ }^{\circledR}$, Draeger, Lübeck, Germany) using a software modification to allow the reduction of xenon consumption under minimal flow conditions. The inspiratory concentration of xenon was measured with an automatically calibrated thermo-conductive device in the anaesthesia machine ( \pm 3 vol\% accuracy).

Air Liquide Deutschland GmbH (Business Unit, Krefeld, Germany) provided xenon of medical quality in steel cylinders for this study.

Infusion of remifentanil was carried out at a base rate of $0.15 \mu \mathrm{g} \mathrm{kg}{ }^{-1} \mathrm{~min}^{-1}$ and titrated according to clinical needs. The remifentanil infusion was increased based on haemodynamic (heart rate, systolic arterial blood pressure), somatic (swallowing, movement) and autonomic sings (flushing, sweating, salivating) at $0.05 \mu \mathrm{g} \mathrm{kg}^{-1} \mathrm{~min}^{-}$ ${ }^{1}$ increments until symptoms were resolved.

Standard treatment of blood loss and fluid replacement strategy were used if necessary.

The standardised instructions included the administration of piritramide $0.05 \mathrm{\mu g} \mathrm{kg}^{-1}$ twenty minutes before the estimated end of surgery as well as a short infusion of metamizole $15 \mathrm{mg} \mathrm{kg}^{-1}$, both as part of the postanaesthetic pain management.

Inhaled anaesthetics were reduced to $0.5 \mathrm{MAC}$ ten minutes before the estimated end of the intervention.

Discontinuation of anaesthesia required completion of all surgical tasks (including bandaging) and complete recovery from neuromuscular block (TOF-Watch $S X^{\circledR}$, Organon Teknika, Eppelheim, Germany).

The return of spontaneous breathing was aided by allowing a rise of end-expiratory carbon dioxide levels up to $6.6 \mathrm{kPa}$.

Extubation of the patients' tracheas required full recovery of the upper airway reflexes, sufficient 
spontaneous breathing (>8 breaths $\mathrm{min}^{-1}, \mathrm{SaO}_{2}>95 \%$ with $\mathrm{F}_{\mathrm{i}} \mathrm{O}_{2}$ at $100 \%$ ) and haemodynamic stability.

Starting with the discontinuation of the anaesthetic, a blinded investigator recorded the emergence times from anaesthesia as part of the secondary outcome parameters. This included the time to extubation, time to awakening (eyes open), time to basic verbal command (squeeze investigator's hand) and time to return of orientation (date, time, place), all determined at $20 \mathrm{~s}$ intervals.

All patients were transferred from the operating room to the post-anaesthetic care unit for recovery. The study investigator recorded the modified 10-point scaled Aldrete scores at 5, 15, 30, 45, $60 \mathrm{~min}$ and at discharge from the PACU.

Pain level, dosage of postoperative analgesics, incidence of nausea and vomiting, use and dosage of antiemetics, as well as vigilance, well-being and energy were rated and recorded at the same intervals. Pain management included piritramide $0.05 \mathrm{mg} \mathrm{kg}^{-1}$ if VAS for pain was rated $>3$.

The primary outcome parameter, as well as the additional measures of cognitive function, was recorded for each patient during three predetermined time intervals. Baseline testing was completed $12-24 \mathrm{~h}$ preoperatively. These tests were repeated in the same order between 6$12 \mathrm{~h}$ and again after 66-72 $\mathrm{h}$ postoperatively.

All instructions on how to perform the tests were given in a standard way by a blinded investigator to ensure uniform collection of data. The assessment took place in a quiet room, reducing outside disturbances. The tests were completed by the patients in about 45-60 min.

The TAP consists of low complexity tasks, using easily distinguishable stimuli that demand a simple motor response from the patient. It is designed to reduce interfering factors, such as sensory and motor failure and disturbances of speech or memory. The test batteries consisted of the subtests for Alertness, Visual Scanning, Divided Attention, Reaction Change and Working Memory. All tests were administered at the highest level of difficulty.

The two groups were compared in terms of test performance normalized to the preoperative baseline assessment and in terms of the number of patients with a decrease of $20 \%$ or more in test performance. A patient with a $20 \%$ decrease in at least $20 \%$ of all tests was considered to be suffering from POCD [15,34].

During the 6-12 $\mathrm{h}$ postoperative assessment, patients were asked to evaluate the anaesthesia and questioned whether they would choose the same procedure for further operations.

Statistical analysis was performed using SPSS 16.0 (SPSS Inc., Chicago, IL, USA); all figures were generated with GraphPad PRISM ${ }^{\circledR}$ (GraphPad Software Inc., La
Jolla, CA, USA). Categorical data were tested with the two-tailed Fisher's exact test and are presented as numbers and per cents of total. Parametric data were analysed with one-way ANOVA and are given accordingly as means and standard error of the means, means and 95\% confidence intervals, means and standard deviation or means and range.

The sample size of this study was calculated for the primary outcome parameter (subtest "Alertness" of the TAP) with a significance level of $\alpha=0.05$ and a power of $\beta=$ 0.8 , considering a difference of $20 \%$ as relevant. Mean values and standard deviations of the primary outcome parameter were taken from the TAP databases (patients $\geq$ 65 years; $n=416 ; 242 \pm 60 \mathrm{~ms}$ ). The trial size was calculated with $\mathrm{n}=18$ and then determined with $\mathrm{n}=20$ patients per group to compensate for possible dropouts. The power calculation was performed with nQuery Advisor $^{\circledR}$, Version 7.0 (Statistical Solutions, Saugus, MA, USA).

\section{Results}

A total of 40 patients were included in this study, equally distributed between the two groups. 39 patients underwent baseline testing prior to the operation and 37 patients completed the $6-12 \mathrm{~h}$ postoperative assessment (18 from the sevoflurane and 19 from the xenon group), while the 66-72 $\mathrm{h}$ assessment was completed by 18 and 14 patients (32 in total). The reasons for drop-outs included refusal of testing and discharge from the hospital previous to assessment and are shown in Figure 1.

The study groups were comparable regarding the distribution of patients' age, weight and height, level of education, gender, Apfel-Score and ASA status (Table 1).

Baseline-testing was scheduled $12-24 \mathrm{~h}$ prior to the operation and all patients underwent testing within that time-frame. The mean time-point of baseline-testing was at 18:33 (18:12-18:54) in the sevoflurane group and at $17: 54$ (17:30-18:18) in the xenon group, resulting in a difference between the two groups (Table 2).

Duration of anaesthesia as well as the type of surgery did not differ between groups. The average end-tidal concentration of volatile anaesthetics for maintenance of anaesthesia was $1.18 \%(0.2)$ for sevoflurane and $53 \%$ (5.2) for xenon. Consumption of remifentanil (intraoperative) and piritramide (intra- and postoperative) were comparable between the two groups.

All recovery-times recorded during the emergence from anaesthesia showed a difference between groups regarding "time to open eyes", "time to react on demand", "time to extubation" and "time to time and spatial orientation" with a significantly faster recovery in the xenon group (Table 3).

There was no significant difference in the length of stay in the PACU (Table 2). The modified Aldrete scores recorded in the PACU were significantly higher 


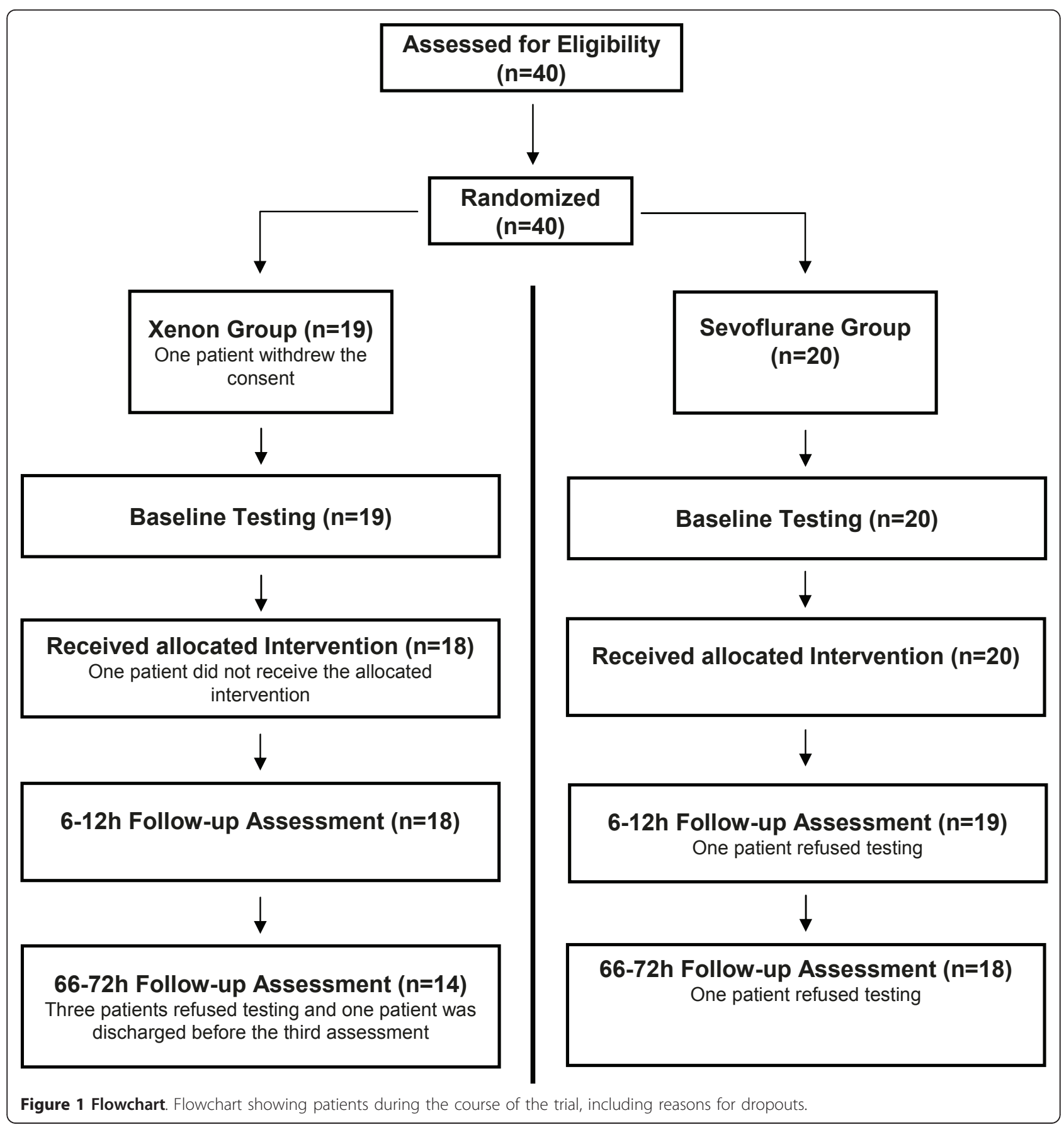

in the xenon group from arrival until $60 \mathrm{~min}$, while results at discharge were comparable. The following other scores from the PACU were in favour of xenon: vigilance at $5 \mathrm{~min}$; well-being at 30 and $45 \mathrm{~min}$ and energy during the complete period (Table 4).

Both postoperative assessments were performed at similar time points (Table 2). The results of patients' self-evaluation of the anaesthesia were homogenous in both groups.
There were no differences between the two groups at the 12-24 $\mathrm{h}$ preoperative baseline assessment of cognitive function with the TAP and the Paper-Pencil-Tests. The postoperative tests at 6-8 and 66-72 $\mathrm{h}$ were normalized to the preoperative baselines.

The subtest "Alertness" as the primary outcome parameter of this study, as well as all other subtests of the TAP and the Paper-Pencil-Tests, did not show a significant difference between the two groups (Figures $2+3$ ). 
Table 1 Patient data

\begin{tabular}{lccc}
\hline & $\begin{array}{c}\text { Sevoflurane } \\
(\mathbf{n}=\mathbf{2 0})\end{array}$ & $\begin{array}{c}\text { Xenon } \\
(\mathbf{n}=\mathbf{1 9})\end{array}$ & $\boldsymbol{P}$-value \\
\hline Age (years) & $70(65-75)$ & $69(65-75)$ & 0,441 \\
Height $(\mathrm{cm})$ & $169(9)$ & $171(6)$ & 0,461 \\
Weight $(\mathrm{kg})$ & $78(12)$ & $78(12)$ & 0,906 \\
Gender male/female & $11 / 9$ & $13 / 6$ & 0,514 \\
Education $<12 / \geq 12 \mathrm{yr}$ & $17 / 3$ & $15 / 4$ & 0,469 \\
ASA I/II/III & $1 / 13 / 6$ & $0 / 13 / 6$ & 0,614 \\
Apfel-Score 1/2/3/4 & $8 / 8 / 3 / 1$ & $9 / 8 / 2 / 0$ & 0,745 \\
\hline
\end{tabular}

Age is presented as mean (range). Height and weight of the patients are given as mean (SD). Gender, school education $<12$ or $\geq 12$ years, ASA classification and Apfel-Score are presented in total numbers.

The number of patients with a decline of $20 \%$ or more in test performance is shown for each test in Table 5 . The Trail Making Test A conducted at 66-72 $\mathrm{h}$ was the only test with a significant difference, while all other Paper-Pencil-Tests and the TAP showed no difference between the groups (Table 5).

Postoperative cognitive dysfunction was defined as a $20 \%$ decline in $20 \%$ of all tests (TAP and Paper-PencilTests combined) $[15,34]$. The incidence was comparable between the two groups at the postoperative evaluations at 6-8 h (xenon 39\%, sevoflurane 32\%; $p=0.737$ ) and 66-72 h (xenon 29\%, sevoflurane $44 \% ; p=0.471$ ).

A decrease in patients' well-being was measured with the Bf-S in both groups 6-12 $\mathrm{h}$ after the operation, while closely returning to baseline values at the second postoperative evaluation (Figure 3). Anxiety assessed
Table 3 Emergence from anaesthesia

\begin{tabular}{lccc}
\hline Time & Sevoflurane & Xenon & $P$-value \\
\hline to open eyes & $8,5(6,7-10,3)$ & $4,6(3,8-5,5)$ & $\leq 0,001$ \\
to react on demand & $8,0(6,1-9,9)$ & $4,6(3,5-5,7)$ & 0,004 \\
to extubation & $8,3(6,5-10,1)$ & $4,6(3,8-5,5)$ & 0,001 \\
to time and spatial orientation & $10,3(8,7-11,8)$ & $7,6(6,1-9,1)$ & 0,014 \\
\hline
\end{tabular}

All times are given in minutes as mean with lower and upper $95 \%$ confidence interval in parentheses.

with the STAI showed a continuous decrease during both postoperative assessments in all patients (Figure 3).

\section{Discussion}

We compared early cognitive function in elderly patients after xenon or sevoflurane anaesthesia in this study.

None of the applied tests detected a significant difference in the incidence of POCD between the xenon and the sevoflurane group.

Selection of the correct testing instruments is essential, since the definition of POCD and its measurement varies in previous studies $[4,35]$. The TAP is a commonly used device to measure attention (further information: http://www.psytest.net) [13,15]. In this study, we used its subtests Alertness, Divided Attention, Visual Scanning, Working Memory and Reaction Change, along with several Paper-Pencil-Tests.

Repeated postoperative assessments might result in a learning effect. The retest reliability of the TAP was shown before [25], although our test intervals were much shorter in this study. The intervals were identical with

Table 2 Anaesthesia data and times of testing

\begin{tabular}{|c|c|c|c|}
\hline & Sevoflurane & Xenon & $P$-value \\
\hline Average gas concentration (\%) & $1,18(0,2)$ & $53(5,2)$ & - \\
\hline \multicolumn{4}{|l|}{ Type of surgery } \\
\hline Trauma & $3(15)$ & $2(10,5)$ & 0,967 \\
\hline Orthopaedics & $2(10)$ & $2(10,5)$ & \\
\hline ENT & $1(5)$ & $1(5,3)$ & \\
\hline Gynaecology & $2(10)$ & $3(15,8)$ & \\
\hline Urology & $7(35)$ & $7(36,8)$ & \\
\hline Neurosurgery & $4(20)$ & $4(21,1)$ & \\
\hline Abdominal surgery & $1(5)$ & $0(0)$ & \\
\hline Anaesthesia time (min) & $151(121-181)$ & $164(121-206)$ & 0,606 \\
\hline PACU time (min) & $65(52-79)$ & $78(64-93)$ & 0,186 \\
\hline Remifentanil consumption ( $\mu \mathrm{g} / \mathrm{kg} / \mathrm{min})$ & $0,13(0,05)$ & $0,16(0,04)$ & 0,065 \\
\hline Intraoperative piritramide (mg) & $5,9(2,4)$ & $5,6(1,2)$ & 0,364 \\
\hline Postoperative piritramide (mg) & $7,9(4,7)$ & $5,8(4,2)$ & 0,625 \\
\hline Preoperative assessment (hh:min) & 18:33 (18:12-18:54) & 17:54 (17:30-18:18) & 0,016 \\
\hline 6-12 h postop. assessment (hh:min) & $15: 42(13: 42-17: 42)$ & $15: 15(13: 10-17: 21)$ & 0,746 \\
\hline 66-72 h postop. assessment (hh:min) & $15: 39(13: 51-17: 27)$ & $15: 36(14: 12-17: 00)$ & 0,969 \\
\hline
\end{tabular}

Average anaesthetic gas concentration is displayed as mean (SD). Type of surgery is presented in number (\% of total). Anaesthesia and PACU times are given as means with the upper and lower $95 \%$ confidence interval in parentheses. Remifentanil values and intra- and postoperative consumption of piritramide are presented as means (SD). Time points of pre- and postoperative testing are shown in hours and minutes with the upper and lower $95 \%$ confidence interval in parentheses. 
Table 4 PACU data

\begin{tabular}{|c|c|c|c|}
\hline & Sevoflurane & Xenon & $P$-value \\
\hline Aldrete A & $8,9(0,9)$ & $9,7(0,6)$ & 0,007 \\
\hline Aldrete 5 & $8,9(1,0)$ & $9,7(0,5)$ & 0,005 \\
\hline Aldrete 15 & $9,1(1,0)$ & $9,7(0,6)$ & 0,023 \\
\hline Aldrete 30 & $9,2(1,1)$ & $9,8(0,3)$ & 0,028 \\
\hline Aldrete 45 & $9,1(1,1)$ & $9,9(0,3)$ & 0,01 \\
\hline Aldrete 60 & $9,1(1,1)$ & $9,9(0,4)$ & 0,034 \\
\hline Aldrete D & $9,8(0,4)$ & $9,7(0,7)$ & 0,88 \\
\hline Vigilance A (A/T/S) & $7 / 12 / 1(35 / 60 / 5)$ & $13 / 5 / 0(72 / 287 / 0)$ & 0,061 \\
\hline Vigilance 5 (A/T/S) & $9 / 11 / 0(45 / 55 / 0)$ & $15 / 3 / 0(83 / 17 / 0)$ & 0,014 \\
\hline Vigilance 15 (A/T/S) & $10 / 10 / 0(50 / 50 / 0)$ & $13 / 5 / 0(72 / 28 / 0)$ & 0,162 \\
\hline Vigilance 30 (A/T/S) & $12 / 8 / 0(60 / 40 / 0)$ & $14 / 4 / 0(78 / 22 / 0)$ & 0,239 \\
\hline Vigilance 45 (A/T/S) & $9 / 7 / 0(56 / 44 / 0)$ & $13 / 4 / 0(76 / 24 / 0)$ & 0,218 \\
\hline Vigilance 60 (A/T/S) & $6 / 5 / 0(55 / 45 / 0)$ & $10 / 3 / 0(77 / 23 / 0)$ & 0,247 \\
\hline Vigilance $D(A / T / S)$ & $16 / 4 / 0(80 / 20 / 0)$ & $17 / 1 / 0(94 / 6 / 0)$ & 0,188 \\
\hline Well-being A (E/G/F/P) & 0/5/10/5 (0/25/50/25) & 0/10/5/2 (0/59/29/12) & 0,111 \\
\hline Well-being 5 (E/G/F/P) & 0/5/10/5 (0/25/50/25) & 1/9/5/2 (6/53/29/12) & 0,18 \\
\hline Well-being 15 (E/G/F/P) & 0/6/10/4 (0/30/50/20) & 0/11/5/1 (0/65/29/6) & 0,094 \\
\hline Well-being 30 (E/G/F/P) & 0/5/11/4 (0/25/55/20) & 0/11/6/0 (0/65/35/0 & 0,023 \\
\hline Well-being 45 (E/G/F/P) & 0/3/10/3 (0/19/62/19) & 0/10/6/0 (0/62/38/0) & 0,021 \\
\hline Well-being 60 (E/G/F/P) & 0/3/8/0 (0/27/73/0) & 0/6/6/0 (0/50/50/0) & 0,265 \\
\hline Well-being D (E/G/F/P) & 0/7/13/0 (0/35/65/0) & 0/11/7/0 (0/61/39/0) & 0,07 \\
\hline Energy A (N/F/P) & 0/5/15 (0/25/75) & $3 / 11 / 4(17 / 61 / 22)$ & 0,003 \\
\hline Energy 5 (N/F/P) & $0 / 5 / 15(0 / 25 / 75)$ & $2 / 12 / 4(11 / 67 / 22)$ & 0,004 \\
\hline Energy 15 (N/F/P) & $0 / 8 / 12(0 / 40 / 60)$ & $2 / 13 / 3(11 / 72 / 17)$ & 0,014 \\
\hline Energy 30 (N/F/P) & $1 / 8 / 11(5 / 40 / 55)$ & 2/15/1 (11/83/6) & 0,005 \\
\hline Energy 45 (N/F/P) & 0/6/10 (0/38/62) & $3 / 14 / 0(18 / 82 / 0)$ & $\leq 0,001$ \\
\hline Energy 60 (N/F/P) & $0 / 5 / 6(0 / 45 / 55)$ & $2 / 11 / 0(15 / 85 / 0)$ & 0,006 \\
\hline Energy D (N/F/P) & $2 / 9 / 9(10 / 45 / 45)$ & $3 / 15 / 0(17 / 83 / 0)$ & 0,005 \\
\hline
\end{tabular}

All values were recorded at the PACU upon arrival (A), after 5 (5), 15 (15), 30 (30), 45 (45), 60 (60) minutes and at discharge (D). Modified Aldrete scores are given as mean (SD). Vigilance, Well-being and Energy are shown in total numbers (\% of total). Vigilance was distinguished as awake (A), tired (T) or sleeping (S). Wellbeing was rated as excellent $(E)$, good $(G)$, fair $(F)$ or poor (P). Energy was classified as normal $(N)$, fair $(F)$ or poor $(P)$.

those suggested by previous studies [13,15]. Alternating equivalent versions of the Paper-Pencil-Tests were used if available, in an effort to minimize learning effects $[4,35]$.

The subtest "Alertness" of the TAP as the primary outcome parameter did not show a significant difference in test performance between the two groups. Additional subtests of the TAP enabled us to monitor a wider spectrum of cognitive functions, but also showed comparable results. The applied Paper-Pencil-Tests detected no difference in test performance.

The number of patients with a decrease of $20 \%$ or more was comparable for each test between the two groups, with exemption of the Trail Making Test A conducted at 66-72 $\mathrm{h}$ postoperatively. The relevance of this finding is limited due to the fact that this test is only one of twelve aspects considered in our calculation of actual postoperative cognitive dysfunction.

The over-all incidence of POCD was high, but comparable between the two groups at both postoperative evaluations (6-8 h: xenon 39\%, sevoflurane $32 \%$; $66-72$ h: xenon $29 \%$, sevoflurane $44 \%)$. Other studies found similar figures, but direct comparison with our study is limited due to the use of different tests and investigated substances $[15,26,36]$.

We were able to show significant differences within each group in comparison to the preoperative baseline in some tests, but could not detect such differences between the two groups.

These findings are in accordance with previous studies $[4,13,15,26]$. None of the investigated anaesthesia regimens showed a significant benefit in terms of reduced incidence and severity of POCD. However all of these studies are limited in their power.

Preoperative testing is crucial, since all calculations are based on these results. The pending operation can pose a stress factor for the patients and hence possibly influence the test results. We chose a 12-24 h period prior to the operation for our assessment in an attempt to limit these effects in comparison to an assessment directly before premedication was given as used by 

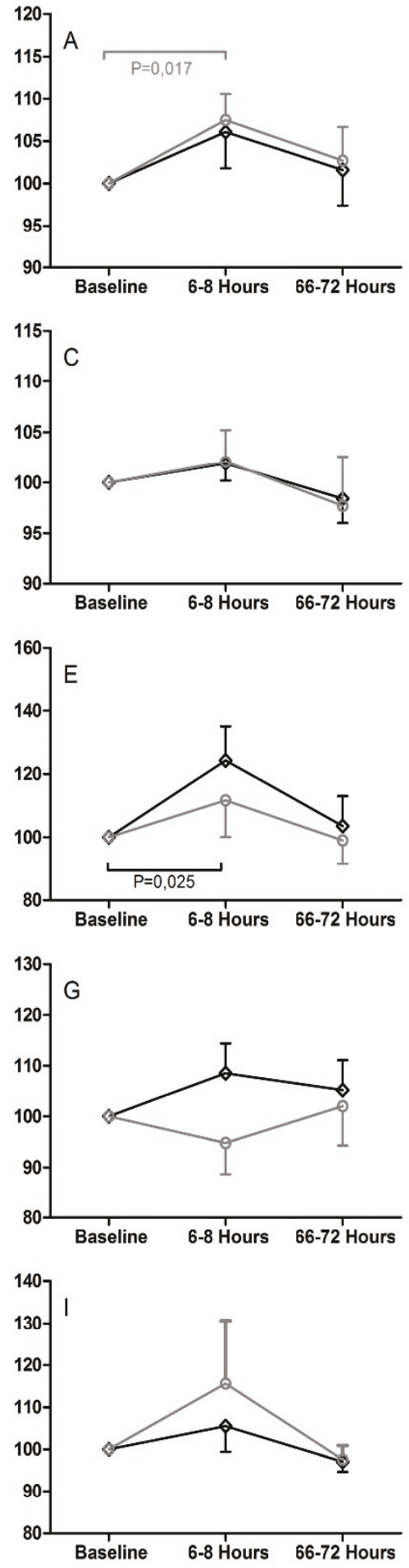
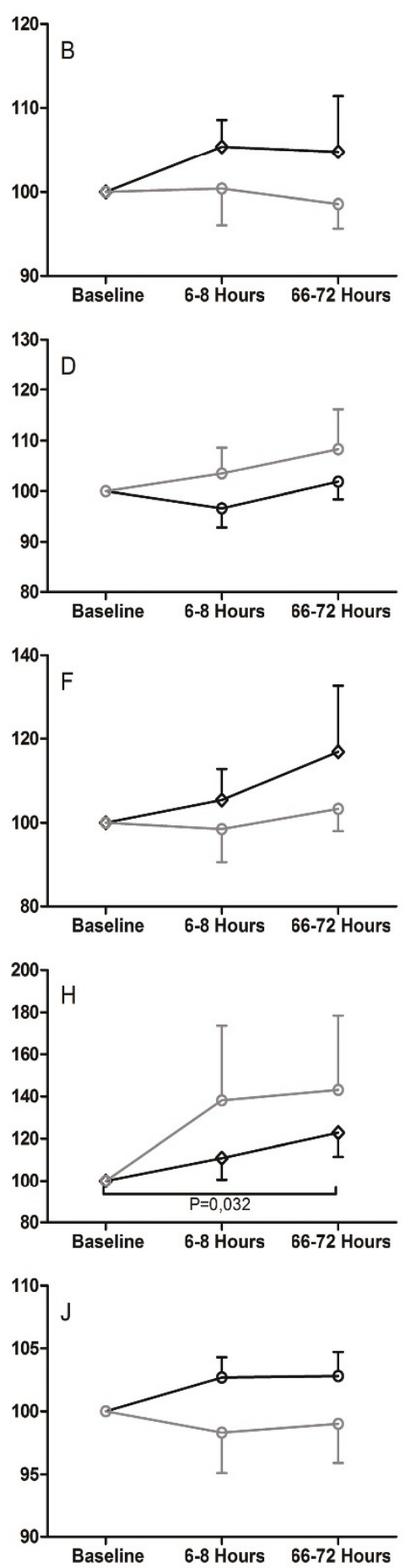

Figure 2 TAP. Cognitive function assessed with the TAP. Subtests Alertness (A+B), Divided Attention (C+D), Visual Scanning (E+F), Working Memory $(\mathrm{G}+\mathrm{H})$ and Reaction Change $(I+\mathrm{J})$. Figure pairs show reaction time on the left and valid reactions on the right. All values are Mean (SEM) and display the change at 6-8 and 66-72 hours normalized to the preoperative baseline. All ordinates are in per cent. Grey lines and open circles display the xenon group, black lines and open squares represent the sevoflurane group. 


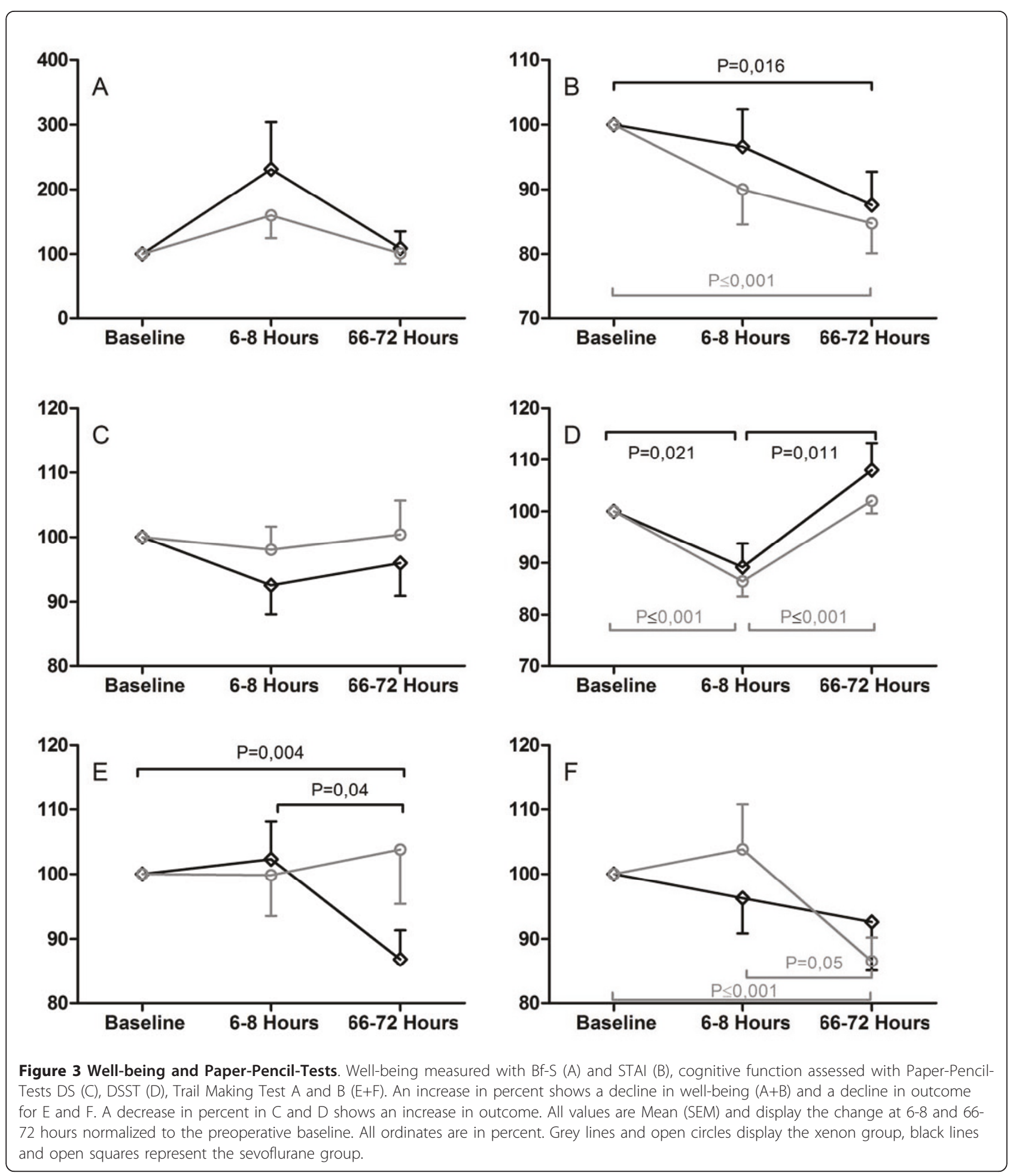

Heavner and colleagues [14]. An earlier time-point would be preferable, but could not be realized in the clinical routine.

Considering the time-frame of $12 \mathrm{~h}$ for the assessment (12-24 h preoperatively), we felt that the difference of
39 min between the mean time-points of testing in the two groups would not have a relevant effect on the results. Variations in time-points of testing are the consequence of choosing a preoperative time-frame over a fixed time-point for the assessment. The actual impact 
Table 5 POCD

\begin{tabular}{|c|c|c|c|c|c|c|}
\hline & \multicolumn{3}{|c|}{$6-8 \mathrm{~h}$ postoperative $>20 \%$} & \multicolumn{3}{|c|}{$66-72$ h postoperative $>20 \%$} \\
\hline & Sevoflurane & Xenon & $P$-value & Sevoflurane & Xenon & $P$-value \\
\hline DS & $5(26)$ & $2(11)$ & 0,405 & $5(28)$ & $3(21)$ & 1 \\
\hline DSST & $4(21)$ & $3(17)$ & 1 & $1(6)$ & $0(0)$ & 1 \\
\hline TMT A & $4(21)$ & $4(22)$ & 1 & $1(6)$ & $6(43)$ & 0,027 \\
\hline TMT B & $4(21)$ & $6(33)$ & 0,476 & $3(17)$ & $0(0)$ & 0,238 \\
\hline Alertness RT & $5(26)$ & $4(22)$ & 1 & $2(12)$ & $2(14)$ & 1 \\
\hline Alertness VR & $0(0)$ & $2(11)$ & 0,23 & $1(6)$ & $1(7)$ & 1 \\
\hline Divided Attention RT & $2(11)$ & $1(6)$ & 1 & $1(6)$ & $2(14)$ & 0,576 \\
\hline Divided Attention VR & $1(6)$ & $1(6)$ & 1 & $2(12)$ & $0(0)$ & 0,488 \\
\hline Visual Scanning RT & $7(37)$ & $3(17)$ & 0,269 & $4(25)$ & $2(14)$ & 0,657 \\
\hline Visual Scanning VR & $316)$ & $3(17)$ & 1 & $3(19)$ & $2(14)$ & 1 \\
\hline Working Memory RT & $3(16)$ & $4(22)$ & 0,693 & $5(31)$ & $3(21)$ & 0,689 \\
\hline Working Memory VR & $5(26)$ & $5(28)$ & 1 & $1(6)$ & $0(0)$ & 1 \\
\hline Reaction Change RT & $3(16)$ & $1(6)$ & 0,608 & $0(0)$ & $0(0)$ & - \\
\hline Reaction Change VR & $0(0)$ & $2(13)$ & 0,202 & $0(0)$ & $1(8)$ & 0,433 \\
\hline
\end{tabular}

Cognitive function assessed with Paper-Pencil-Tests and the TAP. Decline $>20 \%$ to the $12-24 \mathrm{~h}$ preoperative values is presented in numbers (\% of total). PaperPencil-Tests are Recall of Digit Span (DS), Digit-Symbol-Substitution-Test (DSST), Trail Making Test A and B (TMT A, TMT B). Subtests of the TAP were analyzed in terms of mean reaction time (RT) and number of valid reactions (VR).

can not be quantified, but we suspected a justifiable benefit from earlier testing.

The power was calculated for the primary outcome parameter, considering $20 \%$ as a relevant difference. As discussed in previous studies, $10-15 \%$ could be a clinically more relevant value [15]. Regarding the secondary outcome parameters and this consideration, the study might be underpowered.

The high drop-out rate in the xenon group before the second postoperative assessment could have further altered our results.

Sevoflurane was used with an average end-tidal concentration of $1.18 \%(0.2)$, which is equivalent to $75 \%$ of an age-adapted MAC according to Nickalls and Mapleson [33]. Xenon was used with a mean concentration of $53 \%$ (5.2), resembling $84.1 \%$ of a MAC. Since there are no age-adapted MAC values for xenon available, we presumed that the used gas concentrations were equivalent. They match the concentrations used in other studies $[37,38]$.

The times recorded during recovery of anaesthesia were significantly faster in the xenon group. This corresponds with the low blood-gas partition coefficient of xenon (0.115) compared to sevoflurane (0.69) [11]. The results are similar to those described in earlier studies $[13,15,17,39]$.

The scores from the PACU were partially in favour of xenon. The modified Aldrete-scores and the level of energy were higher in the xenon group throughout the recorded time-period. These results are comparable with previous findings $[13,15]$.

The Aldrete-scores were homogenous in both groups at discharge from the PACU. Self-evaluation of the anaesthesia showed no difference between patients from the two groups. Patients' well-being showed a comparable development during the course of the trial (Figure 3).

\section{Conclusions}

In conclusion, xenon anaesthesia enables significantly faster emergence from anaesthesia in the elderly.

No difference in the incidence of POCD could be detected after xenon and sevoflurane anaesthesia. The occurrence was comparable in both groups 6-8 and 66$72 \mathrm{~h}$ after the operation.

\section{Authors' contributions}

JC and MC performed the statistical analysis and drafted the manuscript. MC and RR participated in the study design and coordination. AVF, CS, GS, JC and SR helped to perform the anaesthesia and revised the manuscript. All authors read and approved the final manuscript.

\section{Competing interests}

This study was supported by Air Liquide Deutschland GmbH (donor of xenon).

MC and RR received lecture and consultant fees from Air Liquide Santé International, a company interested in developing clinical applications for medical gases, including xenon.

Received: 25 March 2011 Accepted: 18 May 2011

Published: 18 May 2011

\section{References}

1. Monk TG, Weldon BC, Garvan CW, Dede DE, van der Aa MT, Heilman KM, Gravenstein JS: Predictors of cognitive dysfunction after major noncardiac surgery. Anesthesiology 2008, 108:18-30.

2. Moller JT, Cluitmans P, Rasmussen $L S$, Houx P, Rasmussen $H$, Canet J, Rabbitt P, Jolles J, Larsen K, Hanning CD, Langeron O, Johnson T, Lauven PM, Kristensen PA, Biedler A, van Beem $H$, Fraidakis $\mathrm{O}$, Silverstein $\mathrm{JH}$, Beneken JE, Gravenstein JS: Long-term postoperative cognitive dysfunction in the elderly: ISPOCD1 study. Lancet 1998, 351:857-861. 
3. Gao L, Taha R, Gauvin D, Othmen LB, Wang Y, Blaise G: Postoperative cognitive dysfunction after cardiac surgery. Chest 2005, 128:3664-3670.

4. Newman S, Stygall J, Hirani S, Shaefi S, Maze M: Postoperative cognitive dysfunction after noncardiac surgery. Anesthesiology 2007, 106:572-590.

5. Wappler F, Rossaint R, Baumert J, Scholz J, Tonner PH, van Aken $H_{\text {, }}$ Berendes E, Klein J, Gommers D, Hammerle A, Franke A, Hofmann T, Schulte Esch J: Multicenter randomized comparison of xenon and isoflurane on left ventricular function in patients undergoing elective surgery. Anesthesiology 2007, 106:463-471.

6. Baumert JH, Falter F, Eletr D, Hecker KE, Reyle-Hahn M, Rossaint R: xenon anaesthesia may preserve cardiovascular function in patients with heart failure. Acta Anaesthesio/ Scand 2005, 49:743-749.

7. Schroth SC, Schotten U, Alkanoglu O, Reyle-Hahn MS, Hanrath P, Rossaint R: xenon does not impair the responsiveness of cardiac muscle bundles to positive inotropic and chronotropic stimulation. Anesthesiology 2002, 96:422-427.

8. Baumert JH, Hein M, Hecker KE, Satlow S, Schnoor J, Rossaint R: Autonomic cardiac control with xenon anaesthesia in patients at cardiovascular risk. $\mathrm{Br} J$ Anaesth 2007, 98:722-727.

9. Bein B, Turowski P, Renner J, Hanss R, Steinfath M, Scholz J, Tonner PH: Comparison of xenon-based anaesthesia compared with total intravenous anaesthesia in high risk surgical patients. Anaesthesia 2005, 60:960-967.

10. Lockwood GG, Franks NP, Downie NA, Taylor KM, Maze M: Feasibility and safety of delivering xenon to patients undergoing coronary artery bypass graft surgery while on cardiopulmonary bypass. Anesthesiology 2006, 104:458-465.

11. Goto T, Suwa K, Uezono S, Ichinose F, Uchiyama M, Morita S: The bloodgas partition coefficient of xenon may be lower than generally accepted. Br J Anaesth 1998, 80:255-256.

12. Coburn M, Kunitz O, Baumert JH, Hecker K, Haaf S, Zühlsdorff A, Beeker T, Rossaint R: Randomized controlled trial comparing hemodynamic and recovery effects of xenon or propofol anaesthesia. Br J Anaest 2005, 94:198-202.

13. Coburn $M$, Baumert JH, Roertgen D, Thiel V, Fries $M$, Hein $M$, Kunitz $O$, Fimm B, Rossaint R: Emergence and early cognitive function in the elderly after xenon or desflurane anaesthesia: a double-blinded randomized controlled trial. Br J Anaesth 2007, 98:756-762.

14. Heavner JE, Kaye AD, Lin BK, King T: Recovery of elderly patients from two or more hours of desflurane or sevoflurane anaesthesia. $\mathrm{Br} J$ Anaesth 2003, 91:502-506.

15. Rörtgen D, Kloos J, Fries M, Grottke O, Rex S, Rossaint R, Coburn M: Comparison of early cognitive function and recovery after desflurane or sevoflurane anaesthesia in the elderly: a double-blinded randomized controlled trial. Br J Anaesth 2010, 104:67-174.

16. Lane GA, Nahrwold ML, Tait AR, Taylor-Busch M, Cohen PJ, Beaudoin AR: Anesthetics as teratogens: nitrous oxide is fetotoxic, xenon is not. Science 1980, 210:899-901.

17. Rossaint R, Reyle-Hahn M, Schulte Am Esch J, Scholz J, Scherpereel P, Vallet B, Giunta F, Del Turco M, Erdmann W, Tenbrinck R, Hammerle AF, Nagele $P$ : Multicenter randomized comparison of the efficacy and safety of xenon and isoflurane in patients undergoing elective surgery. Anesthesiology 2003, 98:6-13.

18. Derwall M, Coburn M, Rex S, Hein M, Rossaint R, Fries M: xenon: recent developments and future perspectives. Minerva Anesthesiologica 2009, 75:37-45.

19. Schmidt M, Marx T, Glöggl E, Reinelt H, Schirmer U: xenon attenuates cerebral damage after ischemia in pigs. Anesthesiology 2005, 102:929-936

20. Coburn M, Maze M, Franks NP: The neuroprotective effects of xenon and helium in an in vitro model of traumatic brain injury. Crit Care Med 2008, 36:588-595.

21. Ma D, Yang H, Lynch J, Franks NP, Maze M, Grocott HP: xenon attenuates cardiopulmonary bypass-induced neurologic and neurocognitive dysfunction in the rat. Anesthesiology 2003, 98:690-698.

22. Fries M, Nolte KW, Coburn M, Rex S, Timper A, Kottmann K, Siepmann K, Häusler M, Weis J, Rossaint R: xenon reduces neurohisto-pathological damage and improves the early neurological deficit after cardiac arrest in pigs. Crit Care Med 2008, 36:2420-2426.

23. Homi HM, Yokoo N, Ma D, Warner DS, Franks NP, Maze M, Grocott HP: The neuroprotective effect of xenon administration during transient middle cerebral artery occlusion in mice. Anesthesiology 2003, 99:876-881.
24. Timper A, Kottmann K, Rossaint R, Fries M, Demir F: xenon ameliorates cognitive performance after CPR in pigs. Crit Care Med 2006, 34:A13.

25. Coburn M, Henzler D, Baumert JH, Fimm B, Drüke B, Rossaint R: Influence of a 30 min break on divided attention and working memory in resident anaesthetists on daily routine. Br J Anaesth 2006, 97:315-319.

26. Höcker J, Stapelfeldt C, Leiendecker J, Meybohm P, Hanss R, Scholz J, Bein B: Postoperative neurocognitive dysfunction in elderly patients after xenon versus Propofol Anesthesia for major noncardiac surgery. Anesthesiology 2009, 110:1068-1076.

27. Drummond GB: The Assessment of postoperative mental function. $\mathrm{Br} J$ Anaesth 1975, 47:130-142.

28. Wechsler D: Wechsler Adult Intelligence Scale-Revised. New York: Psychological Corporation; 1981.

29. Reitan RM: Validity of the Trail Making test as an indicator of organic brain damage. Percept Mot Skills 1958, 8:271-276.

30. von Zerssen D: Clinical self-rating scales (CSRS) of the Munich Psychiatric Information System (PSYCHIS München). In Assessment of Depression. Edited by: Sartorius N, Ban TA. Berlin, Heidelberg, New York: Springer; 1986:270-303.

31. Marteau TM, Bekker $\mathrm{H}$ : The development of a six-item shortform of the state scale of the Spielberger State-Trait Anxiety Inventory (STAl). $\mathrm{Br} J$ Clin Psychol 1992, 31:301-306.

32. Aldrete JA: The post-anesthesia recovery score revisited. J Clin Anesth 1995, 7:89-91.

33. Nickalls RWD, Mapleson WM: Age-related iso-MAC charts for isoflurane, sevoflurane and desflurane in man. Br J Anaesth 2003, 91:170-174.

34. Grichnik KP, lisselmuiden AJ, D'Amico TA, Harpole DH Jr. White WD, Blumenthal JA, Newman MF: Cognitive decline after major noncardiac operations: a preliminary prospective study. Ann Thorac Surg 1999, 68:1786-1791.

35. Rasmussen LS, Larsen K, Houx P, Skovgaard LT, Hanning CD, Moller JT: The assessment of postoperative cognitive function. Acta Anaesthesio/ Scand 2001, 45:275-289.

36. Rasmussen LS, Schmehl W, Jakobsson J: Comparison of xenon with propofol for supplementary general anaesthesia for knee replacement: a randomized study. Br J Anaesth 2006, 97:154-159.

37. Fahlenkamp AV, Krebber F, Rex S, Grottke O, Fries M, Rossaint R, Coburn M: Bispectral index monitoring during balanced xenon orsevoflurane anaesthesia in elderly patients. Eur J Anaesthesiol 2010, 27:906-911.

38. Fahlenkamp AV, Peters D, Biener IA, Billoet C, Apfel CC, Rossaint R, Coburn M: Evaluation of bispectral index and auditory evoked potentials for hypnotic depth monitoring during balanced xenon anaesthesia compared with sevoflurane. Br J Anaesth 2010, 105:334-341.

39. Chen X, Zhao M, White PF, Li S, Tang J, Wender RH, Sloninsky A, Naruse R, Kariger $\mathrm{R}$, Webb $\mathrm{T}$, Norel $\mathrm{E}$ : The recovery of cognitive function after general anesthesia in elderly patients: a comparison of desflurane and sevoflurane. Anesth Analg 2001, 93:1489-1494.

\section{doi:10.1186/2045-9912-1-9}

Cite this article as: Cremer et al: Early cognitive function, recovery and well-being after sevoflurane and xenon anaesthesia in the elderly: a double-blinded randomized controlled trial. Medical Gas Research 2011 1:9.

\section{Submit your next manuscript to BioMed Central and take full advantage of:}

- Convenient online submission

- Thorough peer review

- No space constraints or color figure charges

- Immediate publication on acceptance

- Inclusion in PubMed, CAS, Scopus and Google Scholar

- Research which is freely available for redistribution 